\title{
Characterization of (-)-Matairesinol as a Potent Inhibitor of Casein Kinase I in Vitro
}

\author{
Takamasa Yokoyama, ${ }^{a}$ Maiko Okano, ${ }^{a}$ Toshiro Noshita, ${ }^{b}$ Shinji Funayama, ${ }^{b}$ and Kenzo Ohtsuki ${ }^{*}, a$ \\ ${ }^{a}$ Genetical Biochemistry, Graduate School of Medical Sciences, Kitasato University; 1-15-1 Kitasato, Sagamihara \\ 228-8555, Japan: and ${ }^{b}$ Department of Bioscience and Biotechnology, Aomori University; 2-3-1 Kohbata, Aomori \\ 030-0943, Japan. Received November 9, 2002; accepted December 26, 2002; published online January 6, 2003
}

\begin{abstract}
The inhibitory effects of (-)-matairesinol (MTS) isolated from Thujopsis dolabrata var. hondai on the activities of four distinct Ser/Thr-protein kinases [two casein kinases (CK-I and CK-II), A-kinase and C-kinase] were determined in vitro. It was found that (i) MTS inhibits the activities of CK-I and C-kinase $\alpha$ (ID $_{50}=$ approx. $10 \mu \mathrm{M})$ in a dose-depedent manner, but high doses are required to inhibit A-kinase activity $\left(\mathrm{ID}_{50}=\right.$ approx. $\left.90 \mu \mathrm{M}\right)$; (ii) the autophosphorylation of CK-I is more sensitive to MTS (ID ${ }_{50}=$ approx. 0.2 $\mu_{\mathrm{M}}$ ); (iii) MTS inhibits CK-I activity in a manner similar to that observed with CK-I-7 (a CK-I inhibitor); and (iv) the compound inhibits CK-I activity by affecting ATP binding in a mixed type manner. These results indicate that MTS is a potent CK-I inhibitor in vitro.
\end{abstract}

Key words casein kinase I; (-)-matairesinol; potent CK-I inhibitor; Thujopsis dolabrata var. hondai

Recently, (-)-matairesinol (MTS, see Fig. 1) isolated from Symplocos setchuensis, was reported to inhibit HIV replication in H9 lymphocyte cells, and its derivatives exhibit more potent inhibition of the virus in vitro. ${ }^{1,2)}$ We have been studying the mechanical actions of several natural anti-viral substances, including glycyrrhizin $(\mathrm{GL})^{3,4)}$ and anti-oxidant polyphenol containing compounds, ${ }^{5,6}$ in the in vitro assay systems for several distinct protein kinases, such as casein kinases I and II (CK-I and CK-II), cAMP-dependent protein kinase (A-kinase) and $\mathrm{Ca}^{2+}$ - and phospholipid-dependent protein kinase (C-kinase). Recently, we reported that (i) high mobility group protein 1 (HMG1) is a cholesterol-3-sulfate (CH-3S)-binding protein; and (ii) CH-3S acts as an effector of the phosphorylation of HMG1 by CK-I in vitro. ${ }^{7,8)}$ Since the physiological activity of MTS in vitro has been not yet elucidated, the present study was carried out to determine its inhibitory effects on the activities of four distinct Ser/Thrprotein kinases (CK-I, CK-II, A-kinase and C-kinase) in vitro. Here, we describe (i) biochemical characterization of MTS as a potent inhibitor of CK-I in vitro; (ii) the inhibitory kinetics of MTS on the CK-I-mediated phosphorylation of $\alpha$-casein or HMG1 in vitro; and (iii) the MTS-induced selective inhibition of the CK-I-mediated phosphorylation of cellular proteins in the partially purified heparin fraction containing two casein kinases (CK-I and CK-II) from rat liver in vitro.

\section{MATERIALS AND METHODS}

Chemicals $\quad\left[\gamma_{-}{ }^{32} \mathrm{P}\right]$ ATP $(3000 \mathrm{Ci} / \mathrm{mmol})$ was obtained from Amersham Pharmacia Biotech (Arlington Heights, U.S.A.); dithiothreitol (DTT) and a silver staining kit from Wako Pure Chemical Ind. (Osaka, Japan); CH-3S (5cholesten-3 $\beta$-ol sulfate) from Tokyo Kasei Kogyo Co. Ltd. (Tokyo, Japan); myelin basic protein (MBP, a protein subsatrate of C-kinase $\eta$ ), CK-I-7 [ $N$-(2-aminoethyl)-5-chloroisoquinoline-8-sulfonamide (a specific CK-I inhibitor)] from Seikagaku Kogyo (Tokyo, Japan); and $\alpha$-casein, histone IIIS (calf thymus), actin (rabbit skeletal muscle), poly-L-arginine (poly-Arg, about 100 residues), phosphatidylserine (PS) and

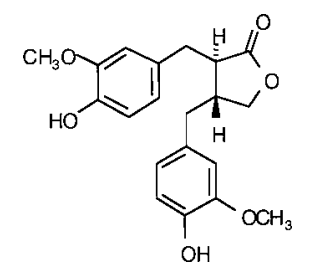

Fig. 1. The Chemical Structure of MTS

diacylglycerol (DG) from Sigma Chemical (St. Louis, U.S.A.).

Extraction of MTS Sawdust of Thujopsis dolabrata SIEB. et ZuCC. var. hondai MAKINO (5.8 kg) was successively extracted three times ( $3 \mathrm{~d}$ each) with $n$-hexane, chloroform and methanol at room temperature. After filtration, the solvent was evaporated under reduced pressure to afford a $n$ hexane extract $(91 \mathrm{~g})$, a chloroform extract $(109 \mathrm{~g})$ and a methanol extract $(54 \mathrm{~g})$. The chloroform extract $(109 \mathrm{~g})$ was dissolved in chloroform (1.01), and then extracted with $1 \%$ $\mathrm{NaOH}(1.5 \mathrm{l})$. The aqueous layer was separated and acidified with $\mathrm{HCl}$, followed by extraction with chloroform. The chloroform layers were combined and washed with $\mathrm{NaCl}$ saturated water (1.01). The concentrated chloroform layer was used as an acidic part of the chloroform extract $(14.0 \mathrm{~g})$.

Isolation and Identification of MTS The acidic fraction of the chloroform extract of T. dolabrata var. hondai (2.8 g) was chromatographed over Florisil (100-200 mesh, Wako Chemicals U.S.A., Inc.) with guidance by positive reaction with $\mathrm{FeCl}_{3}$, using solvents of increasing polarity from chloroform through methanol to give 6 fractions (Fr. I-1 to Fr. I-6). Fr. I-1 $(835 \mathrm{mg})$ was further chromatographyed over Florisil, eluting with chloroform/ethyl acetate (50:1 to $1: 1)$, to give 11 fractions (Fr. II-1 to Fr. II-11). Fr. II-11 (220 mg) was successively subjected to Florisil column chromatography (chloroform/methanol, $10: 1$ ) and preparative TLC (benzene/ethyl acetate, $2: 1)$ to give MTS $(20 \mathrm{mg})$ with a yield of $0.0017 \%$. The spectra of IR, UV, MS, ${ }^{1} \mathrm{H}-$ and ${ }^{13} \mathrm{C}-\mathrm{NMR}$, and $[\alpha]_{\mathrm{D}}$ of the purified compound corresponded exactly to those reported for MTS. ${ }^{9)}$ This is the first report of the isolation of MTS from T. dolabrata var. hondai. 
Protein Kinases Rat liver CK-I (specific activity: 17500 units $/ \mathrm{mg}$ ) was obtained from Promega Co. (Madison, U.S.A.); bovine heart type I A-kinase (specific activity: $400 \times 10^{3}$ units $/ \mathrm{mg}$ protein) from Sigma Chemical (St. Louis, U.S.A.); rat liver C-kinase $\alpha$ (specific activity: $1-2 \mu \mathrm{mol}$ phosphate $/ \mathrm{min} / \mathrm{mg}$ ) purified from Molecular Probes (Oregon, U.S.A.); recombinant human C-kinase $\eta$ (rhC-kinase $\eta$, specific activity: $0.9 \mathrm{mmol}$ phosphate $/ \mathrm{min} / \mathrm{mg}$ protein) and recombinant human CK-II (rhCK-II, specific activity $400 \times 10^{3}$ units/mg protein) from Biomol Research Laboratories Inc. (Plymouth Meeting, PA, U.S.A.).

Assay for the Activitiy of A-Kinase The activity (phosphorylation of histone $\mathrm{H} 2 \mathrm{~B}$ ) of purified A-kinase (bovine heart) was assayed in the prsence of $2 \mu \mathrm{M}$ cAMP, as reported previously. ${ }^{6}$ )

Assays for the Activities of CK-I and CK-II The activity (phosphorylation of $\alpha$-casein or HMG1) of CK-II was assayed in reaction mixtures comprising $40 \mathrm{~mm}$ Tris- $\mathrm{HCl}(\mathrm{pH}$ 7.4), CK-II (approx. $10 \mathrm{ng}), 10 \mu \mathrm{M} \quad\left[\gamma_{-}^{32} \mathrm{P}\right] \mathrm{ATP} \quad(1000$ $\mathrm{cpm} / \mathrm{pmol}), 10 \mathrm{~mm} \mathrm{Mg}{ }^{2+}, 2 \mathrm{~mm}$ DTT, poly-Arg (a CK-II activator, $0.5 \mu \mathrm{g})$ and $\alpha$-casein or HMG1 $(4 \mu \mathrm{g})$. Phosphorylation of HMG1 by CK-I was carried out in the presence of $3 \mu \mathrm{M} \mathrm{CH}-3 \mathrm{~S}$ (an activator of the CK-I-mediated phosphorylation of HMG1 in vitro). ${ }^{7}$ After incubation for $30 \mathrm{~min}$ at $30{ }^{\circ} \mathrm{C},{ }^{32} \mathrm{P}$-phosphorylated $\alpha$-casein or HMG1 (p31) in the reaction mixtures was detected directly by autoradiography after sodium dodecyl sulfate-polyacrylamide gel electrophoresis (SDS-PAGE), as reported previously. ${ }^{4-7)}$

Assay for the Activities of C-Kinase $\alpha$ and C-Kinase $\eta$ The activity (phosphorylation of histone IIIS) of C-kinase $\alpha$ was assyed in the presence of C-kinase activators $(1 \mathrm{~mm}$ $\mathrm{Ca}^{2+}, 25 \mu_{\mathrm{M}}$ PS and $3 \mu_{\mathrm{M}} \mathrm{DG}$ ). Phosphorylation of MBP by C-kinase $\eta$ was carried out in the presence of $1 \mathrm{~mm} \mathrm{Ca}^{2+}$. After the incubation for $30 \mathrm{~min}$ at $30^{\circ} \mathrm{C}$ with the indicated doses of MTS, the ${ }^{32} \mathrm{P}$-phosphorylated histone IIIS or MBP (p21) in the reaction mixtures was detected by SDS-PAGE followed by autoradiography, as previously reported. ${ }^{8)}$

\section{RESULTS AND DISCUSSION}

Inhibitory Effects of MTS on the Activities of Four Distinct Protein Kinases in Vitro The inhibitory effects of MTS on the activities of CK-I, CK-II, A-kinase and C-kinase $\alpha$ were examined in vitro. As shown in Fig. 2A, MTS inhibited CK-I activity (phosphorylation of $\alpha$-casein) in a dose dependent manner $\left(\mathrm{ID}_{50}=\right.$ approx. $\left.10 \mu \mathrm{M}\right)$, but did not affect CK-II activity (phosphorylation of $\alpha$-casein) even at $1 \mathrm{~mm}$. The activity (phosphorylation of histone IIIS) of C-kinase $\alpha$ was inhibited in a similar fashion to CK-I activity $\left(\mathrm{ID}_{50}=\right.$ approx. $10 \mu \mathrm{M}$ ), but required high doses to inhibit A-kinase activity $\left(\mathrm{ID}_{50}=\right.$ approx. $\left.90 \mu \mathrm{M}\right)$. Similar inhibitory kinetics of MTS on CK-I activity were obtained when HMG1 was used as a substrate instead of $\alpha$-casein (Fig. 2B). These results show that MTS inhibits the activities of CK-I and C-kinase $\alpha$ in vitro.

To test the direct effects of MTS on the autophosphorylation of CK-I in vitro, CK-I was incubated with $10 \mu \mathrm{M}[\gamma-$ $\left.{ }^{32} \mathrm{P}\right]$ ATP $(1000 \mathrm{cpm} / \mathrm{pmol})$ in the presence or absence of various doses of MTS. About $80 \%$ of the autophosphorylation of CK-I was inhibited at $1 \mu \mathrm{m}$ and this inhibition was maintained above $1 \mu \mathrm{M}$ (Fig. 3). The 50\% inhibition dose $\left(\mathrm{ID}_{50}\right)$ of

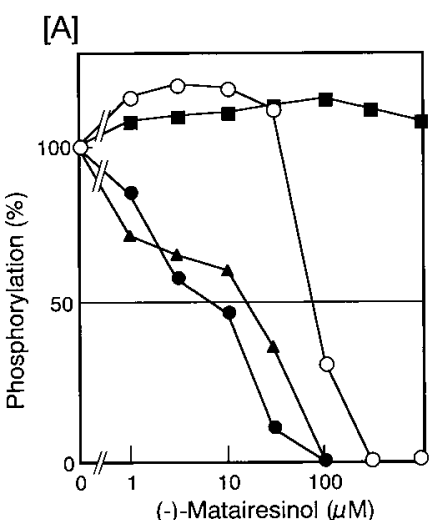

[B]

Fig. 2. [A] The Inhibitory Effects of MTS on the Activities of Four Distinct Protein Kinases in Vitro

Four distinct Ser/Thr-protein kinases (CK-I, CK-II, A-kinase and C-kinase $\alpha$ ) were separately assayed in the presence of the indicated doses of MTS, as described in Materials and Methods. ${ }^{32} \mathrm{P}$-Phosphorylated proteins ( $\alpha$-casein, HMG1 or histone IIIS) in the reaction mixtures were detected by SDS-PAGE followed by autoradiography. The autoradiogram was scanned by a spectrophotometer. $100 \%$ represents protein phosphorylation by each protein kinase in the absence of MTS. CK-I (-), CK-II (ם), A-kinase (O), and C-kinase $\alpha(\boldsymbol{\Delta})$

[B] The Inhibitory Effect of MTS on CK-I Activity Using Two Distinct Protein Substrates in Vitro

CK-I was assayed in the presence of the indicated doses of MTS using $\alpha$-casein or HMG1. ${ }^{32}$ P-Phosphorylated $\alpha$-casein $(\bullet)$ or HMG1 $(\bigcirc)$ in the reaction mixtures was detected by SDS-PAGE followed by autoradiography.

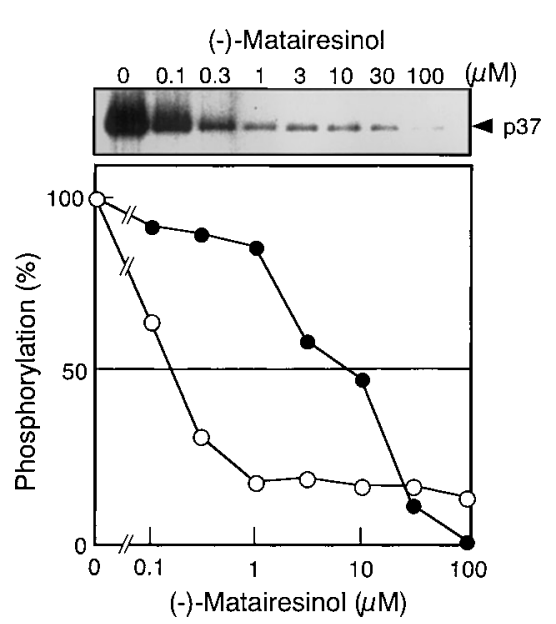

Fig. 3. The Inhibitory Effect of MTS on the Autophosphorylation of CK-I and CK-I Activity in Vitro

CK-I was incubated with $10 \mu \mathrm{M}\left[\gamma_{-}{ }^{32} \mathrm{P}\right] \mathrm{ATP}(1000 \mathrm{cpm} / \mathrm{pmol})$ in reaction mixtures comprising $40 \mathrm{~mm}$ Tris-HCl (pH 7.4), CK-I (approx. $10 \mathrm{ng}$ ), $10 \mathrm{~mm} \mathrm{Mg}^{2+}$ and $2 \mathrm{~mm}$ DTT, and incubated for $30 \mathrm{~min}$ at $30^{\circ} \mathrm{C}$ in the presence of the indicated doses of MTS. ${ }^{32} \mathrm{P}-\mathrm{L}$ abeled CK-I (an autophosphorylated form of CK-I, p37) in the reaction mixtures was detected by SDS-PAGE followed by the autoradiography. The autoradiogram was scanned by a spectrophotometer. $100 \%$ represents autophosphorylation of CK-I in the absence of MTS. Autophosphorylation of CK-I $(\mathrm{O})$ and the CK-I-mediated phosphorylation of $\alpha$-casein (

MTS on the autophosphorylation of CK-I was about one fiftieth the concentration of that required to inhibit CK-I activity on $\alpha$-casein (Fig. 3). Under the same experimental conditions, a similar inhibition of MTS on CK-I activity was obtained when skeletal muscle actin (rabbit) instead of $\alpha$-casein was used as a substrate for CK-I (data not shown). These results suggest that MTS directly binds to CK-I and results in the inhibition of its autophosphorylation in vitro. In contrast, the $\mathrm{ID}_{50}$ of MTS on the autophosphorylation of C-kinase $\alpha$ was found to be approx. $10 \mu \mathrm{M}$, which is about the same dose 


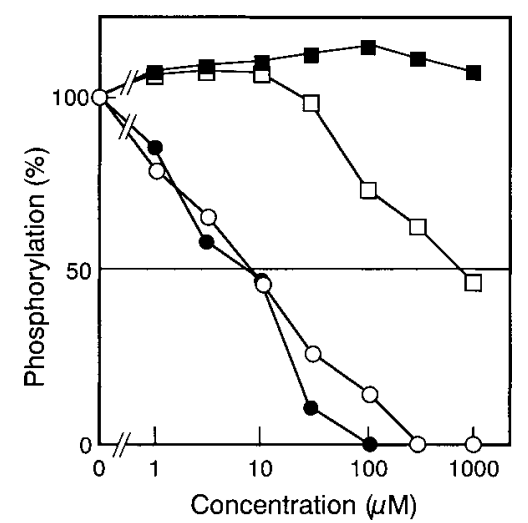

Fig. 4. The Inhibitory Effects of MTS and CK-I-7 on the Activities of CK-I and CK-II in Vitro

The inhibitory effects of MTS and CK-I-7 on the activities of CK-I and CK-II were separately determined in the presence of the indicated doses, as described in Fig. 2A. ${ }^{32} \mathrm{P}$-Labeled $\alpha$-casein in the reaction mixtures was detected by SDS-PAGE followed by autoradiography. The autoradiogram was scanned by a spectrophotometer. $100 \%$ represents protein phosphorylation by each protein kinase in the absence of the two treatments. The inhibitory effect of CK-I-7 on the activities of CK-I $(\bigcirc)$ and CK-II ( $\square$ ); and the inhibitory effect of MTS on the activities of CK-I (-) and CK-II (ם)

as the inhibitory effect on the activity of C-kinase $\alpha$ (Fig. 2A). Similar inhibitory effects of MTS on the activity (phosphorylation of MBP) of C-kinase $\eta$ and its autophosphorylation in vitro were observed (data not shown).

Characterization of MTS as a Selective CK-I Inhibitor in Vitro To characterize the selective effect of MTS on the autophosphorylation of CK-I and the CK-I-mediated phosphorylation of $\alpha$-casein, two inhibitors (MTS and CK-I-7) were compared. The inhibitory kinetics of MTS on CK-I activity were similar to those observed with CK-I-7 $\left(\mathrm{ID}_{50}=\right.$ approx. $10 \mu \mathrm{M}$ ) (Fig. 4). Although CK-I-7 at $1 \mathrm{~mm}$ inhibited about $50 \%$ of CK-II activity, there was no obvious effect of MTS on CK-II activity even at $1 \mathrm{~mm}$. These results show that the sensitivity of CK-II activity to MTS is different from that to CK-I-7 up at $1 \mathrm{~mm}$ in vitro.

Inhibitory Kinetics of MTS on CK-I Activity in Vitro The inhibitory kinetics of MTS on CK-I activity were determined using $\alpha$-casein as a substrate. The $V_{\max }$ value shifted from 45 to $31 \mathrm{nmol} / \mathrm{mg} / \mathrm{min}$ when MTS $(30 \mu \mathrm{M})$ was added to the reaction mixtures (Fig. 5). In contrast, the $K_{\mathrm{m}}$ value $(1.14 \mu \mathrm{M})$ for ATP shifted to $2.06 \mu \mathrm{M}$ under the given experimental conditions. Similar inhibitory kinetics of MTS on the phosphorylation of HMG1 by CK-I were observed (data not shown). These results show that MTS inhibits protein phosphorylation by CK-I by affecting ATP binding in a mixed type manner.

In the present study, MTS has been characterized as a potent CK-I inhibitor in vitro, because (i) MTS inhibits selectively CK-I activity $\left(\mathrm{ID}_{50}=\right.$ approx. $10 \mu \mathrm{M}$ ) (Fig. $2 \mathrm{~A}$ ) by affecting ATP binding in a mixed type manner (Fig. 5); and (ii) at a low dosage $\left(\mathrm{ID}_{50}=\right.$ approx. $\left.0.2 \mu \mathrm{M}\right)$, MTS inhibits the autophosphorylation of CK-I in vitro (Fig. 3). Although CK-I-7 at $1 \mathrm{~mm}$ inhibited about $50 \%$ of CK-II activity, there was no such effect of MTS on CK-II activity (Fig. 4). These results suggest that MTS acts as a selective CK-I inhibitor more than CK-I-7 at above $1 \mathrm{~mm}$ in vitro. Therefore, it is possible to speculate that MTS may inhibit the replication of human immunodeficiency virus (HIV) in H9 lymphocyte cells through its selective inhibition of the CK-I-mediated phos-

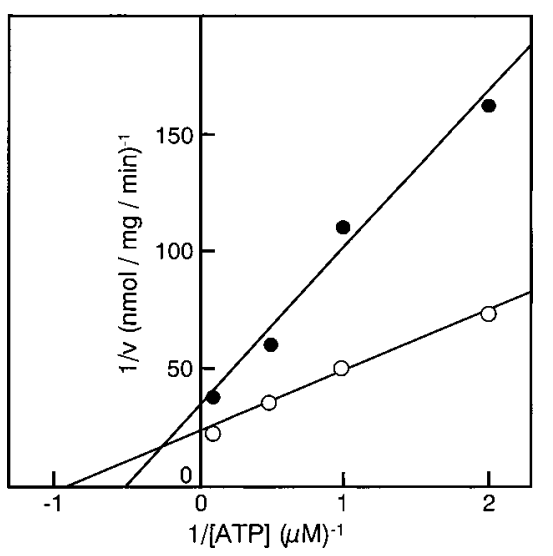

Fig. 5. The Inhibitory Kinetics of MTS on the Phosphorylation of $\alpha$-Casein by CK-I in Vitro

After incubation $\left(30 \mathrm{~min}\right.$ at $\left.30^{\circ} \mathrm{C}\right)$, the radioactivity of ${ }^{32} \mathrm{P}$-labeled $\alpha$-casein on a glass filter was measured with a scintillation spectrometer, as reported previously. ${ }^{10}$ The $K_{\mathrm{m}}$ and $V_{\max }$ values are represented on Lineweaver-Burk plots. The phosphorylation of $\alpha$-casein by CK-I was determined in the absence $(\bigcirc)$ or presence of $30 \mu \mathrm{M}$ MTS (O).

phorylation of viral and cellular proteins involved in HIV replication in HIV-infected cells.

The CK-I family consists of multiple isoforms encoded by seven distinct genes $(\alpha, \beta, \delta, \varepsilon$, and $\gamma 1-3)$ in various mammalian cells. ${ }^{11)}$ Recently, IC261 (3[2,4,6trimethoxyphenyl)methylidenyl]-indolin-2-one) has been characterized as a specific inhibitor of both CK-I $\delta$ and CK-I $\varepsilon$, and it has been demonstrated that this compound inhibits the activities of these two CK-I isoforms $\left(\mathrm{ID}_{50}=\right.$ approx. $\left.1 \mu \mathrm{M}\right)$ in an ATPcompetitive manner in vitro. ${ }^{12)}$ Furthermore, it has been reported that IC261 specifically inhibits the CK-I $\delta$ - and CKI $\varepsilon$-mediated signal transduction involved in cell division, possibly through the regulation of centrosome or spindle function during mitosis. ${ }^{13)}$ Although there is no structural similarity between MTS and IC261, it will be interesting (i) to examine the in vitro phosphorylation of cellular proteins by the MTS-sensitive CK-I isoforms, which are implicated in triggering the progression of HIV replication and in CK-Iregulated biological events, such as DNA replication, DNA repair, mitosis, ${ }^{14-16)}$ and Wnt signaling ${ }^{17)}$; and (ii) to identify the functional mediators, such as p45, specifically phosphorylated by the MTS-sensitive CK-I isoforms at the cellular level.

Acknowledgements This work was supported in part by grants from the Graduate School of Medical Sciences (RP3006, 2002) and the School of Allied Health Sciences (SAHS-A104, 2002), Kitasato University and Grant-in-Aid for Scientific Research (No. 14572098, 2002-2003). We are grateful to Dr. Ian G. Gleadall for critical comments on the manuscript.

\section{REFERENCES}

1) Ishida J., Wang H., Oyama M., Cosentino M. L., Hu C., Lee K., J. Nat. Prod., 64, 958-960 (2001).

2) Abe F., Yamauchi T., Chem. Pharm. Bull., 34, 4340- 4345 (1986).

3) Okuyama E., Suzumura K., Yamazaki M., Chem. Pharm. Bull., 43, 2200-2204 (1995).

4) Maekawa T., Kosuge S., Sakamoto S., Funayama S., Komiyama K., Ohtsuki K., Biol. Pharm. Bull., 22, 667—673 (1999). 
5) Harada S., Haneda E., Maekawa T., Morikawa Y., Funayama S., Nagata N., Ohtsuki K., Biol. Pharm. Bull., 22, 1122-1126 (1999).

6) Kosuge S., Maekawa T., Saito C., Tanaka T., Kouno I., Ohtsuki K., J. Biochem. (Tokyo), 129, 403-409 (2001).

7) Okano M., Kano S., Munakata H., Ohtsuki K., Biochem. Biophys. Res. Commun., 281, 1325-1330 (2001)

8) Sakamoto R., Okano M., Takena H., Ohtsuki K., Biol. Pharm. Bull., 24, 906-911 (2001).

9) Rahman M. M. A., Dewick P. M., Jackson D. E., Lucas J. A., Phytochemistry, 29, 1971-1980 (1990).

10) Karino A., Okano M., Hatomi M., Nakamura T., Ohtsuki K., Biochem. Biophys. Acta, 1472, 603-616 (1998).
11) Fish K. J., Cegielska A., Getman M. E., Landes G. M., Virshup D. M., J. Biol. Chem., 270, 14875-14883 (1995).

12) Mashhoon N., DeMaggio A. J., Tereshko V., Bergmeier S. C., Egli M., Hoekstra M. F., Kuret J., J. Biol. Chem., 275, 20052-20060 (2000).

13) Behrend L., Milne D. M., Stoter M., Deppert W., Campbell L. E., Meek D. W., Knippschild U., Oncogene, 19, 5303—5313 (2000).

14) Tuazon P. T., Traugh J. A., Adv. Second Messenger Phosphoprotein Res., 23, 123-164 (1991).

15) Gross S. D., Anderson R. A., Cell Signal, 10, 699-711 (1998).

16) Eide E. J., Virshup D. M., Chronobiol. Internal., 18, 389-398 (2001).

17) Peters J. M., McKay R. M., McKay J. P., Graft J. M., Nature (London), 401, 345-350 (1999). 